\title{
ANÁLISIS DE LA CONTEXTUALIZACIÓN EN LA NOVELA POLICIACA DE RAMIRO PINILLA: EL GETXO DE POSGUERRA
}

\author{
JaVier Feijoo Morote \\ UNED \\ iesjavierfeijoo@yahoo.es
}

\begin{abstract}
RESUMEN: La obra narrativa de Ramiro Pinilla ha sido, recientemente, objeto de un reconocimiento decisivo por parte del público y la crítica académica especializada. Acorde con su objetivo de contribuir a la construcción de la novela de la memoria crítica, su serie de novelas policiacas formada por Sólo un muerto más (2009), El cementerio vacío (2013) y Cadáveres en la playa (2014) proporciona unas estructuras idóneas: la búsqueda de la verdad y del conocimiento como el único medio de construir un futuro y vencer el olvido. El presente artículo analiza los efectos de la ubicación espaciotemporal elegida para recrear un tiempo perdido en la memoria colectiva de España y transmitir los ecos de una intransigencia meditada y de una contradicción no resuelta entre el pasado y el presente de España.
\end{abstract}

Palabras CLAVE: novela policiaca; memoria histórica; Ramiro Pinilla; Euskadi; Guerra Civil

ABSTRACT: The narrative work of Ramiro Pinilla has recently been acknowledged with an increasing appreciation by academic criticism and the general public. His crime novel series, consisting of Sólo un muerto más (2009), El cementerio vacío (2013) and Cadáveres en la playa (2014) provide the proper structures to his aim to participate in the building of "critical memory novel": the search for 
truth and knowledge as the only mean to build a common future and to defeat oblivion. The present article analyses the effects of the choice of spatiotemporal locations to recreate a time lost in the Spanish collective memory and to transmit the echoes of a meditated intransigence and of an unresolved contradiction between the past and present of Spain.

Keywords: Crime Novel; Historical Memory; Ramiro Pinilla; Euskadi; Spanish Civil War

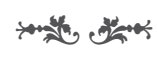

INTRODUCCIÓN

El redescubrimiento en el ámbito nacional de Ramiro Pinilla (Bilbao, 19232014) se produjo a partir del año 2004 con la publicación de su novela Verdes valles, colinas rojas en la Editorial Tusquets. ${ }^{1}$ Los tres volúmenes que la forman (La tierra convulsa, Los cuerpos desnudos y Las cenizas del hierro) obtuvieron, consecutivamente, el Premio Euskadi de Literatura en castellano (2004), el Premio de la Crítica (2005) y el Premio Nacional de Narrativa (2006). Hasta ese momento, su figura y su obra eran prácticamente desconocidas en el panorama literario español e, incluso, en el vasco.

A pesar del exitoso inicio de su carrera literaria con la obtención del Premio Nadal en 1960 por su novela Las ciegas hormigas, y su galardón de finalista del Premio Planeta en 1971 por Seno, la obra de Pinilla ha sido frecuentemente olvidada por la crítica académica especializada. Afortunadamente, a partir de la publicación de Verdes valles, colinas rojas, su nombre ha pasado a situarse como un referente importante de la narrativa española y, desde entonces, esa nueva posición está siendo acompañada de un interés creciente por el estudio crítico de su obra.

Durante más de cincuenta años, Pinilla fue construyendo su propio universo narrativo, de hondas raíces faulknerianas, " "un mundo novelesco intenso y testimonial, crítico con la realidad contemporánea y dialéctico con la memoria histórica" (Alonso 1998: 1). Desde entonces, su recorrido literario se ha caracterizado siempre por marcar unos rasgos específicamente individuales, alejado de las tendencias predominantes en la literatura española.

Por lo que respecta al género policiaco en su obra, y como puede deducirse de la dedicatoria que encabeza la novela Sólo un muerto más -"A Romo P.

\footnotetext{
${ }^{1}$ Es importante señalar que Verdes valles, colinas rojas fue concebida desde el comienzo como un libro único, que podría aparecer por partes o entregas. Por ello, creo preferible describirla como una novela única publicada en tres tomos por razones obvias de extensión y edición, más que como una trilogía.

2 El propio autor ha insistido en la influencia del escritor norteamericano en distintas entrevistas (Celaya 2006, González 2012, Bilbao 2010 o Azancot 2010). En una conversación mantenida con el autor de este artículo el 19 de julio de 2014, reconoció la influencia determinante de una obra concreta de William Faulkner: "Las ciegas hormigas no existiría si yo no hubiera leído Mientras agonizo".
} 
Girca, recordando su Misterio de la pensión Florrie (1944)" (2009: 9)-, su concepto de revisión del género policiaco implica, asimismo, una revisión de su propia trayectoria creadora. ${ }^{3}$ A raíz de la publicación de esta novela, el escritor vizcaíno confesó (Omeñaca 2009: 1) que el policiaco había sido el género en el que inició su andadura a los dieciocho años, y que siempre fue uno de sus predilectos para leer y escribir. Por lo tanto, su regreso a la novela de detectives se entiende también como una necesidad de saldar esa cuenta pendiente con sus primeras novelas policiacas, que él mismo calificó de tristes y de baja calidad, de las que no pudo "extraer ni un sola línea, ni una sola frase interesante para mi dedicatoria":

No es exactamente una nueva experiencia, ni tampoco una sorprendente incursión, porque a los veinte años ya escribí una docena de novelas policiacas con seudónimo, de las que sólo se publicó una. Luego lo dejé pensando que el género novelístico normal era más serio, y éste no tanto. Pero siempre me ha gustado y he leído mucha novela policiaca. Ahora, se me ha ocurrido volver a ella [...]. Porque en Verdes valles, colinas rojas se da el caso de un crimen que no resuelvo, y que reservo para una novela entera posterior. Este pasado año he tenido ocasión de escribirla. (Landaburu 2009: 1)

Por otro lado, también es posible apreciar otras razones en su decisión de cultivar el género policiaco: éste implicaría un retorno a la exploración narrativa de la trama y a la creación de una novela de formas más ajustadas al modelo canónico, incluso en la longitud convencional de la misma. Además, hay que tener en cuenta que, tras la publicación de su voluminosa Verdes valles, colinas rojas y de La higuera (2006), la novela policiaca funcionaría para el autor como el molde idóneo para combinar aspectos más proclives a la reflexión literaria y personal con sus convicciones ideológicas y su firme compromiso político.

En este sentido, la práctica inexistencia de investigaciones sobre su narrativa policiaca ${ }^{4}$ ha dirigido la atención de este estudio hacia unas obras en las que se realiza una particular fusión de las fórmulas del género con la contextualización y cosmovisión particular del autor y que, además, han contribuido cualitativamente tanto al género en España como al conjunto de su obra literaria.

En consonancia con esta atención reciente y teniendo en cuenta la importancia que implica la elección del Getxo de posguerra en la configuración de estas novelas, el objetivo de este estudio se ha centrado en el análisis de la contextualización espacio-temporal en su trilogía de novelas policiacas: Sólo un muerto más (2009), El cementerio vacío (2013) y Cadáveres en la playa (2014b).

En la primera novela de la trilogía, Sólo un muerto más, asistimos a la transformación del protagonista, un librero llamado Sancho Bordaberri en Samuel Esparta, un investigador por cuenta propia que tratará de solucionar un crimen

\footnotetext{
${ }^{3}$ La cita hace alusión a su primera obra, escrita a los veintiún años bajo el seudónimo de Romo P. Girca y publicada en edición de quiosco en 1944, que nunca se reeditó (por decisión propia del autor) y que estaba basada en la famosa novela Seven keys to Baldpate de Earl Derr Biggers, adaptada al cine en numerosas ocasiones: 1916, 1917, 1925, 1929, 1935, 1947 y 1983.
}

${ }^{4}$ A excepción del artículo de Bautista (2011). 
sin resolver ocurrido diez años atrás. Transcurría el año 1935 cuando alguien trató de asesinar en la playa de Arrigúnaga a los gemelos Altube tras dejarlos inconscientes y atarles el cuello a unas argollas de hierro en las que un aldeano sujetaba sus palangres. La altura de la marea hizo que Leonardo, uno de los dos gemelos, muriera y que Eladio, el otro, pudiera sobrevivir al ser descubierto por Lucio Etxe en su paseo matutino por la playa. Tras la investigación, el detective descubrirá que un gemelo se hizo pasar por el otro fingiendo su propia muerte para poder casarse con su prometida, Bidane Zumalabe. El verdadero Leonardo había diseñado unas cadenas de hierro de longitud desigual teniendo en cuenta la profundidad de las mareas para que él pudiera sobrevivir y provocar que su hermano muriera ahogado. Diez años después, Samuel Esparta destapa de nuevo el caso y provoca que Bidane revele la verdad escondida en presencia de Luciano Aguirre, el falangista que da por cerrado el caso tras asestar al gemelo un tiro en la sien.

Por su parte, El cementerio vacío está basada en el asesinato de Anari, una muchacha joven y hermosa del caserío de Belarriena. En este caso, Pedro, un maketo ${ }^{5}$ enamorado de la joven, es rápidamente señalado como el culpable y el detective Samuel Esparta, contratado por dos niños que aseguran con firmeza su inocencia, deberá dedicar todas sus fuerzas a demostrarla aun a costa de la animadversión del pueblo. Su primer paso será averiguar que Anari y Pedro eran novios y pretendían juntos una huida que su hermano mayor, Palento, y su prometido, Domenion, trataron de evitar. Finalmente, con todos los sospechosos presentes en el entierro, el joven Balendin, ciego admirador de Anari se revelará como el responsable del asesinato. Él mismo, para finalizar la trama e inspirado por supersticiones de leyenda, termina suicidándose al lado de su amada con la intención de vivir para siempre con ella en la eternidad del mar, adonde cree que van a parar los cuerpos enterrados en los cementerios marinos.

En la última novela de la serie, Cadáveres en la playa, un Samuel Esparta ya maduro, en 1972, recibe la visita de una mujer que le solicita remontarse treinta y cinco años atrás para investigar la desaparición de quien fue su amor de juventud. En uno de los múltiples fusilamientos masivos realizados durante la guerra civil, apareció súbitamente una persona llevando en una carretilla un cadáver que fue depositado en la misma fosa común de los falangistas. La investigación se centra en los cuatro amigos del desaparecido Estebe Barrondo, que estaban enamorados de la misma mujer, Juana Ezquiaga, y, tras unos interrogatorios redundantes reviviendo la escena de la carretilla con cada uno de los sospechosos, el culpable confiesa su crimen e, incapaz de soportar la culpabilidad, se suicida en el mismo lugar ocupado por la fosa común.

\section{LOS ESPACIOS DEL CRIMEN}

El modelo serial protagonizado por un detective ha sido, desde los inicios del género, uno de los tratamientos más habituales en la literatura policiaca. La

\footnotetext{
${ }^{5}$ Para profundizar en la significación de ese concepto, véase Chacón (2009).
} 
construcción serial (Balló y Pérez 2005: 10) funciona siempre como una especie de pacto entre creador y lector, basado en una "intuitiva valoración del horizonte de expectativas con que cada ficción se formula" y las novelas policiacas remiten explícitamente a esa interacción entre escritores y receptores "a partir de la recepción de elementos unitarios e identificadores con valor de estímulo" (Sánchez Zapatero y Martín Escribà 2010: 191).

En el caso de las novelas policiacas de Ramiro Pinilla, la contextualización serial en el Getxo de la posguerra española conlleva una doble significación: en el sentido policiaco, participar de las estructuras del género desde una contextualización paródica y profundizar en la metamorfosis y las aventuras de un detective en un ámbito no urbano; y en el sentido global de su narrativa, continuar en las coordenadas espacio-temporales del universo ficcional en el que transcurren prácticamente todas sus obras. De hecho, el primer asesinato que debe aclarar el detective Samuel Esparta en Sólo un muerto más fue cometido en una obra anterior, Verdes valles, colinas rojas, con lo que la idea de continuidad entre sus novelas queda así recalcada. Pinilla concentra gran parte de su esfuerzo narrativo en la configuración de un personaje que no había aparecido anteriormente en sus novelas y que servirá de reclamo en las siguientes obras de la serie. Por su parte, el espacio ficcional en el que transcurren las historias sí funciona en ese sentido de atracción y fidelidad ya que sus novelas presentan un mundo ficticio reconocible formado por los lugares y personajes habituales en su obra: la playa de Arrigúnaga, los acantilados de La Galea, el Puerto Viejo de Algorta o la Ermita del Ángel.

Al tratarse de un espacio rural, el área de acción es obligatoriamente más reducida que en la ciudad y resulta inevitable que se repitan los mismos lugares. En la novela urbana, a pesar de la inconmensurable variedad que ofrece la ciudad y con la intención de aprovechar las ventajas de la serie narrativa, "Ios autores acostumbran a mantener una serie de lugares comunes invariables -barrios, ambientes, restaurantes, etc.-, siempre habitados por los mismos secundarios, por los que habitualmente pasa su personaje" (Sánchez Zapatero y Martín Escribà 2010: 295). Esa continuidad en la elección de los espacios forma, como vemos, una doble capa superpuesta: el placer como lector de reconocer los lugares que poblaron las obras anteriores de Pinilla $y$, desde la perspectiva estrictamente policiaca, la gratificación de ir reconociendo esos espacios a medida que avanza la serie del detective.

Insertos en ese contexto, los espacios elegidos para el crimen (las peñas de la playa de Arrigúnaga en Sólo un muerto más, los alrededores de la iglesia de San Baskardo en El cementerio vacío y la arena de la playa de Arrigúnaga en Cadáveres en la playa) asumirán una función determinante en el transcurso de la investigación y en el descubrimiento del culpable. Dos de sus características más significativas serán, por supuesto, su carácter abierto y su ambientación rural. ${ }^{6}$

\footnotetext{
${ }^{6}$ Los crímenes son cometidos en un entorno natural, un territorio ajeno a la propiedad privada, distinguiéndose así de los espacios cerrados habituales en la novela policiaca clásica donde los asesinatos se producían habitualmente en la casa, el templo burgués a profanar. Asimismo, su carácter rural los distancia del ambiente puramente urbano de la novela negra.
} 
El género policiaco y el medio urbano han formado, desde sus orígenes, "una perfecta simbiosis que se ha venido reflejando hasta la actualidad" (Martín Escribà 2009: 41), ya que la novela policiaca se entendía como "una correspondencia entre la modernidad del género y el papel de la ciudad como motor de la modernización" (Resina 1997: 144). Uno de los contrastes inmediatos de la obra de Pinilla es la pretensión de convertir a su protagonista en un detective al estilo urbano de Sam Spade dentro de una aldea vizcaína, poblada por herreros, campesinos, lecheras y criaderos de gallinas, donde no podrá encontrarse con callejones marginales ni antros de juego y prostitución. A pesar de situarse en espacios tan distintos, ambos compartirán una perspectiva de corrupción e injusticia sistemática inserta en la sociedad. ${ }^{7}$ Los espacios que recorre Samuel serán abiertos pero no desconocidos por sus habitantes, como ocurría con los de la gran ciudad, pues no cuentan con su característica fundamental: la posibilidad y conciencia del anonimato (Poe 2006).

A pesar de las evidentes diferencias, el carácter de inviolabilidad atribuido a la casa burguesa se traslada en esta novelas al caserío rural, el espacio de refugio y de orden consagrado a lo largo de los años o siglos de existencia, en el que los objetos y los valores están en un lugar predecible y donde la familia se cree capaz de dominar el azar de la vida exterior. Los caseríos de Getxo representan, por lo tanto, el espacio del ocultamiento, del silencio y de las puertas cerradas y Pinilla los salvaguarda del ámbito del crimen. Tanto las peñas o la arena de la playa como las campas ${ }^{8}$ de la iglesia reivindican la sensación de que no existen espacios de seguridad en la novela policiaca y de que los crímenes son siempre consecuencia de algo terrible y oscuro, refugiado en lo más íntimo del criminal y, en este caso, protegido por la supuesta ternura del sentimiento amoroso.

El espacio rural posibilita así las condiciones de sociedad cerrada y estrechamente relacionada que reclamaba W. H. Auden (1999: 180) en su estudio. De hecho, en estas novelas, tienen una importancia radical pues aparece la necesidad de la sociedad getxotarra de identificar al elemento criminal como algo que viene de fuera, ajeno a su sistema. En Sólo un muerto más, el personaje de Don Manuel trata de convencer a Samuel acerca de la posibilidad de que no hubiera existido realmente un crimen, sino una argucia de los gemelos mal calculada. Su razonamiento se basaba en una clave nacionalista y trágica: era impensable que alguien de su comunidad, un vasco, hubiera cometido un crimen, por lo que era necesario buscar otras posibilidades. El argumento de El cementerio vacío es aún

\footnotetext{
${ }^{7}$ No hay que olvidar que la aparición de la novela negra se explica, entre otras cosas, por el aumento significativo de la densidad demográfica y la aparición de la masa proletaria en las ciudades. Ese proceso también se estaba llevando a cabo en España y, particularmente, en el País Vasco, que contará con la aparición de los inmigrantes (denominados despectivamente como maketos) en su sociedad y con el consecuente choque desestabilizador que ello conlleva para las bases de la sociedad tradicional. La narrativa de Pinilla ha tratado esa perspectiva del miedo, de la llegada inevitable de lo extraño a un orden conocido y estable, incluyendo en algunos de sus personajes esa aversión hacia los extranjeros.

${ }^{8}$ Según el DRAE (22a edición, 2012), la tierra campa es "la que carece de arbolado y por lo común solo sirve para la siembra". El vizcaíno Antonio Trueba, en su Glosario a Cuentos de color de rosa (1864: 418) la definía como "lo mismo que campo, si bien por lo común se llama así a los terrenos que han sido cultivados y se dejan baldíos para pastos".
} 
más explícito, y está basado en esa necesidad de imputar al "otro" las corrupciones del sistema propio: ${ }^{9}$

No es suficiente la terrible saturación de muertos, pues ahora se trata de un muerto diferente, no sólo un hijo de Roque Altube Uribe Gaztañerrota sino un asesinado en un Getxo aún sin guerra, sin invasión franquista... ¿Sabes adónde quiero ir a parar?... ¡Lo mató alguien de entre nosotros! ¿Quién? Se supone que otro vasco. Y aquí está el peligro: no pudo ser un vasco..., si bien en Getxo la inmensa mayoría lo somos. Pero también los hay de fuera, no vascos. Y hubo de ser uno de éstos. Porque, Sancho, los vascos no somos de matar, y menos de ese modo. (Pinilla 2009: 164)

El discurso de la investigación, a medida que transcurre, va relegando esa hipótesis sobre la inocencia vasca, lo que posibilita la disposición policiaca tradicional: todos los personajes pueden ser sospechosos.

\section{El ESPACIO COMO CATALIZADOR DE LA METAMORFOSIS DEL PROTAGONISTA}

En la serie policiaca de Pinilla, el referente espacial se constituye como el catalizador decisivo del doble proceso de transformación del protagonista: por un lado, de librero a detective y, por otro, de novelista imitador de los modelos norteamericanos a novelista que decide trasladar su realidad a la ficción de manera inmediata. En este sentido, el primer capítulo de Sólo un muerto más es plenamente ilustrativo: en él se advierte que la razón del fracaso de Sancho como novelista radica en su obsesión por contextualizar las novelas en escenarios estadounidenses y ajenos. ${ }^{10}$ Cuando el nuevo escritor escucha la revelación que le ofrece la playa de Arrigúnaga ${ }^{11}$ y se aferra a su entorno cercano y conocido, el relato empieza a fluir de manera natural y artística. ${ }^{12}$

En la novela policiaca negra, el detective norteamericano introdujo en el método clásico de investigación la búsqueda de indicios e interrogatorios en las calles y se detuvo especialmente en rastrear los lugares y ambientes del crimen. Teniendo en cuenta el contexto rural inmediato de la vida de Samuel,

\footnotetext{
${ }^{9}$ Un planteamiento que, obviamente, remite a su novela En el tiempo de los tallos verdes (1969).

${ }^{10}$ La referencia a la imitación de los clásicos norteamericanos es en sí misma una fórmula de la novela policiaca española. Por sus referencias quijotescas y a la guerra civil y por la dialéctica establecida entre las ficciones y la propia vida, podemos destacar sus similitudes con Los amigos del crimen perfecto, de Andrés Trapiello, Premio Nadal de 2003.

${ }^{11}$ Con motivo de su noventa cumpleaños, los miembros del Taller que dirigía en Getxo colocaron en la playa de Arrigúnaga una placa con la inscripción: "Aquí empezó todo, por Ramiro Pinilla", en referencia a su idea de que la vida empezó en ese lugar. Lamentablemente, al cabo de unos días, colocaron una esvástica al lado de su nombre, dejando claro que su reconocimiento cultural y social nunca fue fácil en Getxo (comunicación personal citada, 19 de julio de 2014).

12 Como explica García Peinado (2008: 139-140), para provocar ese "efecto de similitud entre dos realidades heterogéneas: el mundo lingüístico del texto y el universo de fuera del texto", es necesario aplicar ciertas condiciones. Esta impresión de naturalidad, de realidad puede apoyarse también "sobre las indicaciones espacio-temporales comunes al texto y fuera de él (desglose cronológico, fechas, horas, lugares, etc.".
} 
las avenidas urbanas y los callejones debían convertirse en escenarios abiertos y naturales. De este modo, el protagonista inicia su nueva vida y su investigación en la playa de Arrigúnaga (escenario de la muerte y, curiosamente, del principio de la vida en la tierra, según el propio autor), interrogando a Lucio Etxe, el testigo que escuchó los primeros gritos de un gemelo, desatando así la secuencia prevista por el asesino.

Los espacios privados del protagonista refuerzan, asimismo, la metamorfosis de Sancho Bordaberri. Tanto el despacho de detective que improvisa en su librería como su residencia familiar refuerzan la perspectiva paródica respecto a los héroes norteamericanos que Samuel Esparta pretende imitar. Por un lado, ubica su despacho en el cuarto trastero de la librería porque se queja de que ésta "no es lugar para que trabaje un investigador" (2009: 79). Una vez instalado, el despacho funciona como el centro de operaciones del detective, donde "recopila los hechos, extrae conclusiones y explora salidas de futuro" (Balló y Pérez 2005: 37). Ese espacio físico facilita, asimismo, su transformación íntima y colectiva en detective privado, y tanto sus enemigos como sus futuros clientes podrán encontrarle en ese lugar en las siguientes novelas de la serie; será allí donde Samuel recibirá los encargos de sus próximos casos así como las habituales amenazas de los antagonistas de los detectives para tratar de detener su investigación. ${ }^{13}$

En relación a su residencia familiar, surge otra contradicción paródica: Sancho comparte la soltería habitual de los detectives (incluso el clima de cierta tensión sentimental con su secretaria), pero, dadas sus circunstancias personales y las condiciones socioeconómicas de posguerra, debe vivir con su hermana y su madre (excepto en la última novela, en la que ésta ya ha fallecido). ${ }^{14}$

\section{LA POSGUERRA ESPAÑOLA Y LA MEMORIA CRÍTICA. LA RESTAURACIÓN DEL ORDEN MORAL Y LA PÉRDIDA DE LA INOCENCIA}

En su acercamiento a la definición del género, Iván Martín Cerezo (2006: 39) señalaba que los dos elementos básicos de todo relato policiaco son el crimen y su investigación. En base a esos dos elementos, la lectura moral de un crimen se basa en que "la sociedad debe tomar el lugar de la víctima y, por consideración a ésta, demandar restitución o concederle perdón" (2006: 41). El crimen abre así una herida en la sociedad, destruye la confianza en los demás y, por ello, debe ser resuelto para tratar de restaurar el orden moral.

La novela policiaca clásica de entreguerras introducía en sus textos una cantidad significativa de ideología conservadora y sus acciones detectivescas iban dirigidas a la protección del orden burgués establecido. A pesar de sus

\footnotetext{
${ }^{13}$ Estas amenazas llegarán a cumplirse en forma de agresión física por parte de los falangistas, quebrantando así la tradicional imagen de estabilidad de ese espacio contrapuesto "a la continua inestabilidad de los escenarios por lo que han de desarrollar las investigaciones" (Balló y Pérez: 37).

14 De acuerdo con la terminología de García Peinado (1998: 157), en este caso, la vivienda del héroe podría entenderse como prolongación de la personalidad de Sancho Bordaberri y como réplica paródica del detective Samuel Esparta.
} 
grietas e inconvenientes, confiaban en el sistema y en el bienestar de la clase a la que pertenecían. De hecho, al analizar sus crímenes, estos eran percibidos por el detective y por muchos novelistas como ataques procedentes de los nuevos valores desestabilizadores de las clases populares. Por consiguiente, la misión del investigador consistía en resolver el crimen, conseguir tranquilizar a la clase dominante y restituir la seguridad tras la amenaza. Por su parte, la novela policiaca negra se caracterizó por concebir el crimen como un producto de la sociedad capitalista occidental y se situaba, por tanto, en un contexto urbano y contemporáneo. La crítica social que subyacía en los textos no proponía un nuevo esquema social sino la denuncia de las injusticias y las corrupciones de un sistema que abanderaba teóricamente la libertad y la igualdad.

De acuerdo con esto, hay que recalcar que una de las principales consecuencias de la contextualización de las novelas policiacas de Pinilla consiste, precisamente, en la ruptura de la fórmula clásica y en la imposibilidad de llevar a cabo ningún tipo de restablecimiento. Consecuentemente, la resolución del crimen no conllevará una restauración del orden ni una defensa de los valores de la autoridad establecida: hay una desconfianza total en el sistema de orden fascista, carente de autoridad moral y basado en el poder bélico y la violencia para su dominación.

Esta crítica política tan directa y explícita tiene una importancia decisiva en estas novelas, pues su autor siempre estuvo firmemente ligado a la defensa de la memoria histórica y reiteró en sus entrevistas la necesidad de desvelar la verdad oculta durante el franquismo. Como explica Ignacio Muñoz López en su tesis doctoral (2009: 3), "Pinilla está dentro del grupo denominado 'memoria crítica': plantean una estrecha correlación entre el pasado y su herencia presente, asumiendo las consecuencias de un conflicto que condenó al olvido a buena parte de sus protagonistas, pero con el firme propósito de restituir su memoria". En este sentido, la represión franquista constituye un elemento crucial del contexto de sus novelas policiacas y de su propia intención narrativa: dejar testimonio de la crudeza de aquella realidad de miedo y muerte. El propio autor recalcó este propósito en sus declaraciones:

Tengo la obsesión por haber vivido esa época, y por el desconocimiento que se tiene hoy de todo aquello. Un auténtico genocidio que la gente joven desconoce. $Y$ he puesto un empeño personal para recordarlo, y siempre que pueda meteré caña. En la guerra un bando cometió muchas más barbaridades que el otro. Estas además "legalizadas". Pero dejemos la guerra y vayamos a la posguerra. Siguieron siete años de genocidio sistemático. Eso lo tengo que contar en algún lado. Doscientos mil muertos, y todos con la sentencia firmada por Franco a la hora del café. Eso no se sabe hoy, y por ello cuando vea al juez Garzón le daré un abrazo. ¡Joder! Es que este hombre está empeñado en sacar a la luz aquel genocidio, y no puede. Pero saldrá y se sabrá, porque hay que denunciarlo, recordarlo y hacer justicia con las víctimas. (Landaburu 2009: 3)

Las novelas policiacas de Pinilla exploran, a través de su contextualización, las razones de la necesidad de la memoria en una sociedad. La 
lucha de Samuel Esparta es, pues, contra el olvido, en busca del reconocimiento de los valores de una vida humana, tratando de lidiar contra la impunidad de los crímenes: ${ }^{15}$

El crimen se cometió en 1935, y supongo que si no se halló al culpable fue porque no se trató de un crimen político. Más tarde, Franco habría dicho: "Esos vascos no echarán en falta a uno de los suyos después de estar perdiendo a tantos". La policía, los municipales y los jueces hicieron muy poco, cuatro preguntas y adiós muy buenas. De modo que hoy, en 1945, aún tenemos al asesino coleando por ahí. ¿Por qué todos, incluido yo, hemos olvidado este asunto durante tantos años? Es que Franco tenía razón, fue un tiempo con demasiados muertos, los de la guerra inminente y los de la represión, que aún no ha cesado. ¿Cómo detenernos en un cadáver que ni siquiera tenía el respeto del pueblo? (Pinilla 2009: 16)

De este modo, Samuel, con su tenaz voluntad quijotesca, trata de formular los valores humanistas de libertad y honestidad individual, ofreciendo la clave para un verdadero resurgimiento moral de la sociedad. Y para ello, no duda en defender la memoria, el recuerdo de lo ocurrido y alimentar así la confianza en una vida alternativa que, sin embargo, tras los desenlaces, quedará expuesta y desnuda. ${ }^{16}$ El espejismo de la restauración del orden tras la comisión de un crimen queda patente en los finales de las tres novelas y ocupa un plano decisivo en su obra, pues Samuel no se ha convertido en caballero para defender el sistema sino para llevar a cabo su impulso de honor personal y literario. Hay que tener en cuenta que, en la posguerra, ese orden estaba representado por las autoridades fascistas que personificaban los valores contrarios a la memoria y la reparación moral, y como le recuerda Eladio Altube a Samuel: "Aquí la autoridad es Luciano; si abres la boca, el que iría a la cárcel o a otro sitio serías tú" (2009: 75) o como ocurre en la escena de la paliza de los falangistas:

Llueven patadas sobre mi cuerpo. Dos botas con gran destreza, botas no de una persona sino de dos, botas de pie derecho hundiéndose en mi carne.

-Eres un cabezota, nos obligas a hacer esto. ¿No sabes que ahora la justicia la administramos nosotros? (Pinilla 2009: 126)

A pesar de la opinión mayoritaria del pueblo y de los representantes de la autoridad, Samuel se niega a aceptar su condición de marginado, pues su código de honor tiene una vocación de reparación social y no descansará en su afán de

\footnotetext{
15 En palabras de Vázquez Montalbán (1991: 17), "aquel que recuerda se convierte en desestabilizador, porque el que recuerda puede soñar con el salto hacia el futuro y de nuevo retomar el discurso de la utopía".

${ }^{16}$ Resulta inevitable relacionar, en este sentido, el significado de estas novelas con su obra $L a$ higuera, publicada en 2006. En ella, la higuera constituye el centro simbólico de toda la obra: un árbol plantado sobre una tumba que representa, además de la nueva vida que fluye de la violencia y el odio de la guerra civil, un testimonio de esa época de barbarie, un monolito de la culpa y la memoria que se niegan a desaparecer, y como el asesinato del gemelo Altube o los miles de asesinatos de la posguerra, la sombra de un secreto que conviene ocultar (Alonso 2007: 1).
} 
justicia, aunque para ello sea necesario saltar por encima de las condiciones sociales y jurídicas de su contexto inmediato:

En una situación normal, en un país normal, acudiríamos a la autoridad, a la policía. Pero sufrimos una sangrienta dictadura militar: ¿ir con un solo crimen, y además por vulgares motivos civiles, a quienes siguen fusilando a miles en las cárceles después del "cautivo y desarmado el ejército rojo la guerra ha terminado", de hace seis años? (Pinilla 2009: 248-249)

Más allá de la recreación de una mente criminal, en estas novelas se aprecia un destacado interés en el fenómeno social de la culpabilidad colectiva: sus novelas presentan la lucha que libra consigo misma la sociedad rural de Getxo para tratar de olvidar un asesinato cometido años atrás. El olvido es una presencia social y en la novela parece ser el verdadero culpable que el detective pretende desenterrar. En Cadáveres en la playa, Higinio Sanjuanena, el bañero testigo del fusilamiento masivo y de la víctima añadida a la fosa común, es el desencadenante de toda la acción pues la tenacidad del recuerdo no le ha permitido sostener su silencio por más tiempo:

-Alguna vez había que empezar a hablar de todo aquello -digo.

-De todo aquello -repite sordamente-. Pero ¿por qué yo ahora? Llevo muchos años deseando no haber visto nada.

-El mundo debe saber lo que ocurrió. (Pinilla 2014: 29-30)

Los crímenes de estas novelas fueron perpetrados en los años circundantes a la Guerra Civil, ${ }^{17}$ por lo que los casos quedaron cerrados sin que una investigación oficial completa pudiera llevarse a cabo. Tras el reguero de muerte anónima y necesidad de olvido que ella provocó, deberá ser un detective aficionado el que emprenda una nueva investigación incluso en los años cercanos a la Transición: "Hablas de tiempos... Pues, bien: hoy no es tiempo de investigar un crimen político del 37. ¿Qué juez se atrevería a procesar a ese Echabarri y compañía?... El franquismo sigue vivo" (2014: 88). La posibilidad de la muerte y el asesinato seguía presente en España ${ }^{18}$, tanto en los fusilamientos oficiales (como el de Toribio Belarritabena) como en la represión cotidiana de los vencedores. En este sentido, el contexto de la novela, el Getxo de posguerra, será precisamente el que posibilite la originalidad de plantear una novela policiaca en un entorno inédito. Las palabras de Martín Cerezo acerca del género permiten subrayar esta singularidad: "La literatura policiaca difícilmente podrá florecer en una sociedad no estabilizada, no burguesa o en un Estado que no cuente con un sistema de libertades y derechos transparentes y reales [...], allí donde cualquier persona

\footnotetext{
17 Sólo un muerto más (1935), El cementerio vacío (1947) y Cadáveres en la playa (1936).

18 Paul Preston calcula en su obra Holocausto español (2011: 29) que "en el conjunto de España, tras la victoria definitiva de los rebeldes a finales de marzo de 1939, alrededor de 20.000 republicanos fueron ejecutados". Por su parte, Stanley G. Payne (2013: 7) propone la cifra aproximada de 30.000 .
} 
puede ser declarada culpable de un crimen sin necesidad de un juicio justo" (2006: 76).

Pese a ello, los asesinatos que investiga Samuel Esparta no están relacionados directamente con las circunstancias políticas y represoras del régimen, sino que participan de un origen más sentimental. En coherencia con la conocida capacidad de Ramiro Pinilla de presentar a los personajes como seres individualizados con todas sus razones y contradicciones interiores, los crímenes parecen proceder de una aparente raíz benévola en el interior de los asesinos: en los tres casos, se trata de asesinatos por amor. ${ }^{19}$ En El cementerio vacío, esa palabra sobrevuela constantemente el texto aunque tratada desde un punto de vista delirante cuya explicación habrá que encontrar en el espíritu de la sociedad rural donde Samuel realiza sus investigaciones y en su capacidad para la creencia en leyendas y mitos tan ancestrales como irracionales.

La última novela de la serie, Cadáveres en la playa, refuerza la idea de la pérdida de la inocencia tras la guerra civil (todos los sospechosos admiten que ellos podrían ser los asesinos y que habían deseado la muerte de la víctima) y el sentimiento de culpabilidad que, en este caso, es reconocida individualmente provocando que el caso termine, al igual que en las otras novelas, con la muerte del criminal.

\section{LA MEMORIA CRÍTICA Y LA CRÍTICA SOCIAL}

El focalizador de las novelas policiacas de Pinilla, "el punto desde el que se contemplan los elementos" (Bal 1985: 110) coincide con el personaje protagonista de la historia, por lo que el lector observará los acontecimientos por medio de la mirada dual de Sancho/Samuel, quien se convierte en protagonista y narrador de su propia novela. Esta elección de narrador homodiegético y focalización interna implica que los espacios recorridos en la investigación sean presentados a través de la mirada del detective, que será el encargado de transmitir la interpretación de todos los signos al lector. ${ }^{20}$ Asimismo, la decisión de situar el crimen en un espacio abierto obliga al detective a recorrer distintos lugares de Getxo e ir recogiendo así testimonios de la realidad social.

\footnotetext{
${ }^{19}$ En estas novelas, se presentan crímenes fraguados por el deseo amoroso y por el ansia egoísta de personajes trastornados. Este motivo tan recurrente $y$, a la vez, tan decisivo en la configuración de la historia y la memoria nos recuerda a la raíz de los asesinatos en varias novelas de Javier Marías, como Corazón tan blanco o Los enamoramientos, en las que "Marías nos presenta el lado oscuro del ser humano, lo que cada uno de nosotros sería capaz de llegar a hacer en nombre del amor, al encontrarse en ese estado de enamoramiento que la mayoría de las veces viene descrito de manera idealizada y que teóricamente, pero sólo teóricamente, nos hace ser mejores, pero que en determinadas circunstancias nos puede llevar a cometer el acto más execrable" (López 2013: 25).

${ }^{20}$ Para definir el estatuto del narrador, Gerard Genette (1972: 302) establece una oposición de nivel: el narrador está fuera (extradiegético) o dentro la ficción (intradiegético) y una oposición que afecta a la relación del narrador con la historia que cuenta según esté ausente de ella (heterodiegético) o sea su propia historia (homodiegético). En el caso de estas novelas, hablamos de un narrador intradiegético-homodiegético.
} 
Desde el punto de vista de la literatura española, los intentos de adaptación del género policiaco han ido sostenidos, en su mayoría, por un afán de crítica social y de representación de la realidad española contemporánea. En el caso de Pinilla, la intención crítica se mantiene, pero en un contexto temporal del pasado, por lo que será inevitable hallar en sus obras referencias a la vida cotidiana en la posguerra. Para ello, el autor no dudará en introducirse desde la perspectiva del protagonista en la intrahistoria de los personajes y del protagonista. Estas alusiones a sus condiciones de vida y a su conexión con los espacios concretos del mundo real pretenden subrayar la relación entre los individuos y su entorno social, ya que "a través de las formas de vida se ofrece un material informativo importante a la hora de caracterizar a los personajes, vinculándolos con su entorno" (Martín Escribà 2009: 49).

En este sentido, el lenguaje juega un papel de contextualización muy importante, ya que se utilizan constantemente vasquismos como sinsorgo, ${ }^{21}$ palabras del euskera (iribio ${ }^{22}$, ugerdo ${ }^{23}$ ), coloquialismos ("percebe"), vulgarismos ("cafecoleche") o expresiones como "iLo que no vale, guardabajo por la Galea!" (2009: 23). Del mismo modo, se ilustra en multitud de escenas el carácter del País Vasco, con su espíritu siempre predispuesto a las apuestas o con las descripciones de Bilbao como centro de referencia para todos los pueblos cercanos. ${ }^{24}$

En relación a la importancia que la novela otorga a la memoria de la represión franquista en la posguerra, es lógico que el pueblo de Getxo, como espacio físico, reproduzca con intención crítica la realidad de aquellos años. Con ese propósito, se describen escenas como la irrupción violenta de los falangistas en la vida cotidiana: "Desde 1937 nadie quiere tenerlos cerca y menos que se dirijan directamente hacia uno. El que precede a los otros dos cruza el umbral de la caseta y entonces oigo a Eladio un «iArriba España!» bastante desfallecido. El recién llegado hace un amplio gesto con el brazo como borrando algo en el aire" (2009: 73). El bando vencedor, en su intento por cambiar la historia, también tuvo que rebautizar calles, plazas y avenidas con nuevos nombres, subrayando de este modo la importancia que el poder siempre ha otorgado históricamente al lenguaje y a la negación del pasado: 25 "Todos los pueblos y ciudades de España, todos, cuentan con una rebautizada Avenida del Ejército, que es por donde entraron los conquistadores franquistas en la guerra: así empezó el horror" (2009: 80).

\footnotetext{
${ }^{21}$ Corrupción del euskera senzurge: Insustancial, hablador sin gracia, tonto (Arriaga 1896: 255).

22 Del verbo irabiau: "revolver, batir", revuelto, agitado (Agud y Tovar 1991: 36).

${ }^{23}$ Del euskera ugerdo: sucio, arrastrado (Arriaga 1896: 277).

24 "Bilbao fue el huevo fundacional del comercio, y lo sigue siendo. Es una animosa ciudad llena de mostradores que ofrecen al cuerpo lo más primario para una felicidad elemental" (Pinilla 2009: 26).

25 "El pasado es indestructible. Tarde o temprano vuelven las cosas; y una de las cosas que vuelven es el proyecto de abolir el pasado". Cita apócrifa atribuida a Jorge Luis Borges en la coproducción cinematográfica hispanoargentina Tango (1998), dirigida por Carlos Saura.
} 
La guerra ha modificado, pues, la vida de todos, y los personajes son conscientes de que ésta se ha convertido en el nuevo punto de referencia social, de ahí que sea habitual que las personas se reconozcan por el papel que tuvieron ellas o sus familiares en la contienda (2009: 107):

Eres Bordaberri [...]. Hijo de Vicente. Vicente estuvo con Félix en los montes. -Se refiere a la guerra-. Pero unos vuelven y otros no... La madre, ¿bien?

Elise siempre fue una mujer entera, salía a descubierto cuando los Junkers alemanes pasaban sobre nuestras cabezas para bombardear Bilbao, el aeropuerto de Sondika o la industria de la Ría, pero también se les podía ocurrir soltar sus bombas sobre Getxo, a modo de entrenamiento; yo prefería verlos bajo techado. Desde la muerte de nuestro padre, ella fue en el hogar la figura fuerte. (Pinilla 2009: 137)

Ramiro Pinilla incluye, asimismo, en su espacio de ficción la narración de la vida cotidiana, deteniéndose, por supuesto, en aspectos como el gastronómico, que en los primeros años de posguerra era un elemento omnipresente en las preocupaciones diarias: "Ama no deja de hablar mientras comemos lentejas de estraperlo y un huevo a la plancha con patatas cocidas, a falta de aceite" (2009: 62). La novela se adentra de este modo en el interior de las casas y de la realidad socioeconómica de la posguerra describiendo, por ejemplo, las condiciones laborales de su hermana como costurera quien, en los días que trabaja en casa, pierde la comida incluida en el jornal. En la segunda novela, Elise iniciará relaciones con el dueño de un ultramarinos, lo que supondrá para la familia un almacén surtido de alimentos; el hambre se constituye así como el primer criterio en el espacio de supervivencia de la posguerra: "Aceite de oliva, ora pro nobis" (2013: 40). Por su parte, Cadáveres en la playa, situada en 1972 se detiene en describir, entre otros detalles, los platos del menú diario de la taberna de Gervasio donde Sancho come todos los días, subrayando así una diferencia significativa respecto a las primeras décadas de posguerra.

Estas novelas presentan, además, para la configuración del espacio narrativo, abundante información sobre la cultura literaria y el mundo editorial. En la segunda novela, El cementerio vacío, Sancho pudo crear con los tebeos que guardaba de antes de la guerra una sección infantil en su librería, como sala para fomento de la lectura. La importancia de ese tipo de literatura en la infancia es crucial, y en este aspecto, vuelca Pinilla toda su memoria de infancia, enumerando sus publicaciones preferidas: Flash Gordon, Dale Arden, el Mago Merlín y el Agente Secreto X-9. Estos recuerdos contribuyen a la identificación del personaje de Sancho como alter ego del escritor, pues él mismo ha explicado en varias ocasiones ${ }^{26}$ cómo los tebeos fueron su modo de descubrir el estallido de la guerra: "No ha llegado y ya no lo traerán porque hay guerra. Pensé que si aquella guerra era capaz de dejarme sin mi Aventurero, había que tomarla en serio" (Pinilla 2013: 12).

\footnotetext{
${ }^{26}$ En la comunicación personal citada o en el blog de Lucía Martínez Odriozola: <http://momodice.blogspot.co.uk/2011/06/ramiro-pinilla-el-itinerario-por-getxo.html>.
} 
La inclusión de Sólo un muerto más como obra física y real dentro del espacio narrativo de la ficción ${ }^{27}$ es utilizado también como instrumento para profundizar en la relación de una obra literaria y el mundo real que le sirve como referente. El oficio real de librero de Sancho Bordaberri permite, asimismo, tratar temas como las costumbres lectoras del pueblo, que son, por supuesto, escasas: "No me haré rico en este negocio, pero sobrevivimos gracias a que, hace años, por iniciativa de Koldobike, incorporamos la sección de papelería, es decir, estas dos gomas de borrar" (Pinilla 2014: 20).

En este sentido, conviene resaltar la conexión especialmente autobiográfica de estas obras y el autor, que puede comprobarse en las continuas referencias al mundo del libro como objeto de consumo, en el que Ramiro Pinilla tuvo una participación destacada, sobre todo, a partir de la creación de su editorial Libropueblo. El espacio rural elegido para contextualizar su creación literaria le permite ahondar en este tipo de consideraciones, configurando al libro desde una triple perspectiva:

1. Un elemento mitológico que contiene la verdad revelada. ${ }^{28}$

2. Un elemento desestabilizador y peligroso para el poder: "Al día siguiente, había ante la lonja cinco camisas azules con el correaje negro, acompañados de dos municipales. «QQué clase de propaganda reparte usted aquí?», me increparon. "Son papeles de todo el mundo, libros», oí a mi espalda. Era Koldobike" (2009: 28-29).

3. Un objeto que debe entrar en el mercado y cuyo valor debe fijarse: "«Vale una peseta», le oí decir al primer cliente, quien depositó el papelito sobre el cuarto baúl y se llevó el libro. ¿Con qué criterio lo eligió? Con ninguno. ¿Con qué pautas asignó Koldobike precio a cada ejemplar? ¿Quizá por el grosor del lomo?" (2009: 28).

Asimismo, como objeto de mercado, el libro no puede desligarse de las condiciones socioeconómicas de su entorno, por lo que los temas de la censura y el oficialismo franquista también aparecerán en la novela. De hecho, su librería depende de la venta de sus libros para la educación y todas esas obras están impregnadas de la terminología fascista de posguerra: el periodo de la guerra se representa con "Años triunfales" 29 y la Iglesia se encarga de supervisar y editar todas estas obras. El tono crítico de la narración aparece en esos casos con fuerza: "En vísperas de cada octubre, la librería se llenaba de estos efluvios, que pronto pasaban y volvíamos a las otras ficciones, las del resto del año" (2009:61).

\footnotetext{
${ }^{27}$ Esa inclusión también es una pieza característica de la construcción del proceso ficcional en la segunda parte de El Quijote.

${ }^{28}$ Es interesante recordar, al respecto, la conversación que sirve de introducción a su obra Antonio B. El ruso (1977, reedición de 2007), en la que el protagonista no es capaz de diferenciar entre la realidad y la ficción inserta en una novela, así como el intento de agresión real que sufrió el autor en Getxo a manos de un vecino, a raíz del éxito de su primera novela, Las ciegas hormigas (1960), que se sintió agredido por haber relatado los episodios de familias recogiendo carbón (comunicación personal citada, 19 de julio de 2014).

29 1936: Año triunfal I; 1937: Año triunfal II y 1938: Año triunfal III.
} 
La novela recurre constantemente a la referencia de acontecimientos históricos como los desencuentros políticos de Franco con la Falange que aparecen al hablar de la censura que tuvo que pasar la primera novela de Sancho Bordaberri, Sólo un muerto más, en la ficción: su publicación se explica atendiendo al distanciamiento entre ambos después de toda la represión llevada a cabo por los falangistas. Este esfuerzo por otorgar verosimilitud a la existencia de la obra de ficción dentro de la ficción de la segunda novela es reforzado explícitamente por el comisario: "un prematuro indicio de cambio por parte del burócrata de turno, quizá contagiado de una nueva mentalidad política" (2013: 78). Desde ese punto de vista, teniendo en cuenta que El cementerio vacío se sitúa en 1947, tanto las autoridades como los vecinos de Getxo se mostrarán sorprendidos de que en el velatorio de Anari se permita una concentración de personas ocupando la calle. Ese mínimo gesto basta para que la ilusión brote, en realidad, sin motivos: "¿Significa que esa insólita manifestación callejera es el preludio de un nuevo tiempo de añorada libertad?" (2013: 38).

La decisión de encuadrar la narración en Getxo comporta, asimismo, la aparición de la crítica al nacionalismo vasco. Las primeras líneas de El cementerio vacío ya plantean el problema que la novela va a tratar: "Esta vez, fue un maketo. No respetó ni a san Baskardo. Los guardias lo salvaron de ser descuartizado por la gente de la romería. Lo tienen en la perrera del Ayuntamiento" (2013: 9). Estas líneas centran su significado en torno a la dialéctica entre civilización y barbarie: la aparición del "otro", presunto agresor y alterador de la civilización que un colectivo ha construido a base de tradiciones. Sin embargo, es esa sociedad la que se encuentra dispuesta a matarlo por una sospecha, lo que provoca que la supuesta autoridad deba encerrarlo en una perrera dispuesta para animales. El hecho de que el crimen ocurriera en la romería de San Baskardo y el posterior intento de linchamiento colectivo también son representativos del carácter de una sociedad que no pretende renegar de su raíz feudal, construida en torno a un calendario religioso de supersticiones sagradas. De igual modo, Pinilla, con su habitual acento irónico dirigido a los sofismas del nacionalismo vasco, no deja de recalcar que los falangistas (como los asesinos de las tres novelas) son vascos: "Luciano Aguirre es del pueblo, ¿no lo sabías? De Las Arenas de toda la vida" (2009: 75).

Desde esa perspectiva crítica, cabe destacar la intención profundamente satírica de las escenas de Luis Federico Larrea, representante de la clase alta del barrio de Las Arenas de Getxo, que reflejan expresamente la problemática social como la representación de una lucha de clases (característica también de los años de posguerra) que Ramiro Pinilla siempre defiende: "Poco me faltó para indicarle que el mejor reloj la lechera lo tenía en su estómago para recordarle a cada paso que no había desayunado, pero no quise perturbar su entusiasmo" (2009: 213). Los esfuerzos del aristócrata por medir el pueblo en pasos son vistos desde una perspectiva irónica y el personaje representa de manera hiriente la distancia real entre las clases sociales: "Ninguna nube pasa por su semblante; continúa sonriendo con esa aparente inocencia que a los dueños de un buen bolsillo les permite mecerse sobre cualquier mundo en llamas" (2009: 216-217). 
El sentido paródico de estas novelas tiene uno de sus pilares en el contraste entre la sociedad norteamericana y la sociedad vizcaína. ${ }^{30}$ De hecho, todas las alusiones espaciales sirven para subrayar la distancia entre el universo norteamericano, construido en base a la mitología literaria y audiovisual, y la vida real y cotidiana de los pueblos de Vizcaya. ${ }^{31}$ La percepción de ese universo estadounidense es muy importante, además, en el proceso de configuración del mundo posible de la novela y de Sancho Bordaberri como personaje real a la manera de Don Quijote cuando asimila la existencia de los demás caballeros andantes a la suya propia:

¡Marlowe y Spade son héroes a contracorriente! -exclamó-. Arriesgan su vida por defender a inocentes, a débiles, a doncellas en peligro. Llevan a criminales ante la justicia. No se paran en barras para denunciar lo denunciable. Desenmascaran a corruptos, hipócritas y extorsionadores. ¡Son los últimos caballeros! (Pinilla 2009: 32)

El contraste entre ambas sociedades es evidente y potencia la contradicción entre la sociedad capitalista y el mundo rural, lo que explicaba el fracaso de las primeras novelas de Sancho, puesto que los maestros norteamericanos tenían la sociedad que describían delante de sus ojos, y no debían invertir demasiada imaginación en la descripción de ciudades de población masificada y un sistema de peligro y violencia sistemáticos. El reto de Sancho, por tanto, vuelve a ser cervantino: "Ellos no han de inventar nada, el que tienes que inventar eres tú, porque en Getxo no ocurre nada" (2009: 32). Ese universo norteamericano, además, no existe como referente para todos los habitantes de su comunidad, de ahí que la irrupción en sociedad de un personaje de un universo ajeno como un detective privado, ataviado además de corbata y sombrero americano provoque un choque mental paródico e inevitable. ${ }^{32}$ Asimismo, también destaca la importancia del espacio identificado como "Las Américas", otro producto mental que perdura en la sociedad española desde el Renacimiento como símbolo del "otro mundo": ese será el destino de Vicente, el maketo de En el tiempo de los tallos verdes y aparecerá también en El cementerio vacío como algo remoto e irreversible: "yo no quería que la mataran, sólo que alguien se la llevara a las Américas" (2013: 93).

Esa oposición social y cultural permite tratar el proceso de transformación de la sociedad industrial, uno de los temas más importantes de toda la narrativa de Ramiro Pinilla, y sus contradicciones e injusticias formarán, por tanto, parte de

\footnotetext{
30 En este sentido, es necesario destacar el concepto de los mundos posibles de Karl Popper (1996: 12), según el cual existen tres tipos de mundos: "el físico, el de los estados mentales y, finalmente, el de los productos mentales (entre los que se encuentran las creaciones artísticas)". Estos tres mundos también existen, a su vez, dentro del mundo propio de la ficción, y de ese modo, el universo de las novelas policiacas de los maestros Hammett, Chandler y sus seguidores aparecerá a su vez como producto mental en las novelas de Pinilla.

31 "Las campanadas de la iglesia de San Baskardo me devuelven al mundo. ¿Qué hago yo sentado en esta piedra del viejo Molino de La Galea?" (Pinilla 2009: 25).

32 "Nunca había visto a nadie en la playa con corbata, y sombrero americano" (Pinilla 2009: 47).
} 
la construcción del espacio social de la ficción novelesca. A diferencia de la mayoría de las novelas policiacas, ese impacto de las nuevas condiciones sociales no será reflejado desde el punto de vista urbano sino desde la perspectiva del mundo rural vizcaíno que, inevitablemente, también soporta las nuevas ideas y contradicciones. En ambas novelas, las figuras de los grandes terratenientes industriales (como Efrén Bascardo) aparecen de un modo muy secundario, por lo que en Sólo un muerto más, Joseba Ermo y los gemelos Altube serán los representantes de la figura del patrono y de la incipiente sociedad mercantilista; en particular, Eladio Altube se vanagloria por haber introducido en el pueblo avances como el tractor o la cría industrial de aves, y se caracteriza además, por un particular desprecio hacia el resto del mundo con un ilimitado afán de lucro y usura: "Es de dominio público que estos empleados les duran muy poco a los Ermo y al Altube, por maltrato y cobrar una miseria, y muchos de ellos no aguantan ni el mes y desaparecen sin recibir la primera paga" (2009: 81).

A pesar de todo, las coordenadas de Getxo siguen siendo rurales, lo que puede comprobarse, por ejemplo, en la relación entre Bidane y Eladio, en extremo decorosas y tradicionales: ninguno de los dos había estado en casa del otro a pesar de verse durante cinco años, y el novio tuvo que esperar uno de luto para vivir juntos en Berango, en el piso de los gemelos y cuatro años después, trasladarse al caserío ancestral de la familia de ella, Zumalabena. La novedad está en que el caserío funcionará como residencia y no como tierra de la que vivir.

El sentido de irrecuperabilidad del pasado y la defensa de los valores de conservación de la naturaleza aparecen con más intensidad en la última novela de la serie, Cadáveres en la playa, un canto de tono melancólico y doliente por la destrucción inevitable de la naturaleza y de las imágenes de la infancia:

Aunque no ponemos palabras a nuestro pensamiento, algunos, o todos, o yo solo, atribuimos esta resignación a la fatalidad, convertida en segunda naturaleza que arrastramos desde la guerra. ¿Cómo comparar la simple pérdida de una playa con lo mucho ya perdido? Nos limitábamos a contemplar el doloroso aspecto que ofrecía nuestro escenario de la infancia y a maldecir la industrialización. (Pinilla 2014: 10)

En su obra póstuma (Sobre el estilo tardío, 2009) Edward Said argumenta con ejemplos de distintos artistas la alteración que sufre la naturaleza del tiempo en la última fase de la vida de los hombres y cómo el pasado y el futuro se inmiscuyen con determinación en la vivencia del presente. De acuerdo con esta idea, este artículo analiza cómo Ramiro Pinilla, tras la publicación de los tres tomos de su obra magna, Verdes valles, colinas rojas, trata explícitamente en sus últimas obras el tema de la recuperabilidad del pasado desde un punto de vista personal y colectivo, sin angustias, sin rencores y desde una perspectiva crítica vitalista. El periodo tardío de Pinilla no puede entenderse, pues, como una fase de descomposición sino como una etapa más en la construcción de su yo narrativo. ${ }^{33}$ Dentro de ese proceso, sus novelas policiacas no se conciben como obras

${ }^{33}$ La proximidad de la muerte del artista se abre camino en estas obras, y de modos muy distintos. 
de armonía o resolución, sino como ecos de una intransigencia meditada y de una contradicción no resuelta entre el pasado y el presente de nuestro país.

\section{OBRAS CITADAS}

Agud, Manuel,y Tovar, Antonio (1991): Diccionario etimológico vasco, tomo VI. Guipúzcoa, Diputación Foral.

Alonso, Santos (1998): "El espejo de la memoria", Revista de Libros, n. ${ }^{\circ}$ 19-20. Disponible en <http://www.revistadelibros.com/articulos/el-espejo-de-la-memoria> [última visita: 30.07.2015].

— (2007): "Una fábula dialéctica", Revista de libros, n . ${ }^{\circ} 125$. Disponible en: <http:// www.revistadelibros.com/articulos/una-fabula-dialectica> [última visita: 30.07.2015].

Arriaga, Emiliano (1896): Lexicón etimológico, naturalista y popular del bilbaíno neto / compilado por un chimbo, con apéndice a sus vuelos cortos. Bilbao, Tipografía de S. De Amorrortu.

Auden, W. H. (1999): "La vicaría de la culpa". En: La mano del teñidor. Buenos Aires, Adriana Hidalgo editora.

Azancot, Nuria (2010): "Las ciegas hormigas fue mi explosión de libertad", El cultural, 8 de enero. Disponible en <http://www.elcultural.es/revista/letras/Ramiro-PiniIla/26416> [última visita: 30.07.2015].

Bal, Mieke (2009): Teoría de la narrativa [1985]. Madrid, Cátedra.

Balló, Jordi, y Pérez, Xavier (2005): Yo ya he estado aquí. Ficciones de la repetición. Barcelona, Anagrama.

Bautista Naranjo, Esther (2011): "Sólo un muerto más, de Ramiro Pinilla, o el Quijote en clave detectivesca", Espéculo. Revista de Estudios Literarios, n 47. Disponible en <https://pendientedemigracion.ucm.es/info/especulo/numero47/muertomas. html> [última visita: 30.07.2015].

Bilbao, Jon (2010): "Conferencia con objeto de la reedición de Las ciegas hormigas en la librería Troa de Getxo", latertuliadelagranja.com, 24 de febrero. Disponible en <http://www.latertuliadelagranja.com/?q=book/export/html/182> [última visita: 30.07.2015]

Celaya, Beatriz (2006): "Ramiro Pinilla", dosdoce.com, 10 de noviembre. Disponible en <http://www.dosdoce.com/articulo/entrevistas/3039/ramiro-pinilla> [última visita: 30.07.2015]

Chacón Delgado, Pedro José (2009): "Las vergüenzas desnudas: el concepto de maketo en la novelística de Ramiro Pinilla", Letras de Deusto, n. ${ }^{\circ} 39$, pp. 167-192.

García Peinado, M. A. (1998): Hacia una teoría general de la novela. Madrid, Arco Libros. Genette, Gerard (1989): Figuras III [1972]. Barcelona, Lumen.

En este sentido, una obra como La higuera (2006) puede entenderse como la coronación a una vida entera de esfuerzo estético y Aquella edad inolvidable (2012) como la asunción melancólica de la irrecuperabilidad del pasado. 
González, Enric (2012): "Ramiro Pinilla y Enric González o los secretos de la vida", Jotdown, julio. Disponible en <http://www.jotdown.es/2012/07/ramiro-pinilla-y-enric-gonzalez-o-los- secretos-de-la-vida> [última visita: 30.07.2015]

Landaburu, Ander (2009): "Entrevista a Ramiro Pinilla", El País. Babelia, 31 de enero. Disponible en <http://elpais.com/diario/2009/01/31/babelia/1233363014_850215.html> [última visita: 30.07 .2015 ]

López López-Pielow, Fátima (2013): “Estructura indagatoria en la narrativa de Javier Marías de Corazón tan blanco a Los enamoramientos". En Javier Sánchez Zapatero y Àlex Martín Escribà (eds.): Historia, memoria y sociedad en el género negro: literatura, cine, televisión y cómic. Santiago de Compostela, Andavira, pp. 25-32.

Martín Cerezo, Iván (2006): Poética del relato policiaco (de Edgar Allan Poe a Raymond Chandler). Murcia, Servicio de Publicaciones de la Universidad de Murcia.

Martín Escribà, Àlex (2009): "Análisis de un escenario negro: Barcelona como identidad literaria". En Javier Sánchez Zapatero y Àlex Martín Escribà (eds.): Geografías en negro. Escenarios del negro criminal, Barcelona, Montesinos, pp. 41-54.

Martínez Odriozola, Lucía (2011): "Ramiro Pinilla, el itinerario por Getxo y un queso fresco", momodice.blogspot.com, 7 de junio. Disponible en <http://momodice.blogspot.co.uk/2011/06/ramiro-pinilla-el-itinerario-por-getxo.html> [última visita: 30.07.2015]

Muñoz López, Ignacio (2009): La reivindicación de la memoria colectiva en la narrativa española contemporánea (1986-2006): Ramiro Pinilla, Rafael Chirbes y Manuel Longares. Tesis doctoral inédita. Universidad Autónoma de Madrid.

Omeñaca, Nuria (2009): "Entrevista a Ramiro Pinilla", Heraldo de Soria, 9 de julio. Disponible en <https://foroabiertodenovelanegra.wordpress.com/2009/07/12> [última visita: 30.07 .2015$]$

Payne, Stanley (2013): "The history war", Wall Street Journal, 13 de abril. Disponible en <http://www.wsj.com/articles/SB10001424052702303302504577325594229771470 $>$ [última visita: 30.07 .2015 ]

Pinilla, Ramiro (1944): Misterio de la pensión Florrie. Bil-bao, Moderna.

_ (1960): Las ciegas hormigas [2010]. Barcelo-na, Tusquets.

— (1969): En el tiempo de los tallos verdes. Barcelo-na, Destino.

(1972): Seno. Barcelona, Planeta.

(1977): Antonio B., El ruso, ciudadano de tercera [2007]. Barcelona, Tusquets.

(2004): Verdes valles, colinas rojas. 1. La tierra convulsa. Barcelona, Tusquets.

(2005a): Verdes valles, colinas rojas. 2. Los cuerpos desnudos. Barcelona, Tusquets.

(2005b): Verdes valles, colinas rojas. 3. Las cenizas del hierro. Barcelona, Tusquets.

(2006): La higuera. Barcelona, Tusquets.

(2009): Sólo un muerto más. Barcelona, Tusquets.

- (2013): El cementerio vacío. Barcelona, Tusquets.

(2014a): Comunicación personal, 19 de julio.

(2014b): Cadáveres en la playa, Barcelona, Tusquets.

Poe, Edgar Allan (2006), "El hombre de la multitud", Bifurcaciones. Revista de estudios culturales urbanos, n. ${ }^{\circ}$ 6. Disponible en <http://www.bifurcaciones.cl/006/bifurcaciones_006_reserva.pdf.> [última visita: 30.07.2015. 
Popper, Karl, y Eccies, J. C. (1980): El yo y su cerebro. Barcelona, Labor.

Preston, Paul (2011): Holocausto español. Barcelo-na, Debate.

Resina, Joan Ramon (1997): El cadáver en la cocina: la novela criminal en la cultura del desencanto. Madrid, Anthropos.

Sánchez Zapatero, Javier, y Àlex Martín Escribà (2010): "Teoría e historia de las sagas policiales en la literatura española contemporánea", Dicenda. Cuadernos de Filología Hispánica, vol. 28, pp. 289-305.

Saura, Carlos (1998): Tango. Película, Coproducción hispanoargentina.

Trapiello, Andrés (2003): Los amigos del crimen perfecto. Barcelona, Destino.

Trueba, Antonio (1864): Cuentos de color de rosa. Madrid, Librería de Leocadio López.

Vázquez Montalbán, Manuel (1991): "La novela española entre el posfranquismo y el posmodernismo". En Ivan Lissorgues (ed.): La Rénovation du Roman Espagnol depuis 1975. Toulouse, Presses Universitaires du Mirail, pp. 13-25. 